\title{
ON GOSPERS FORMULA FOR THE GAMMA FUNCTION
}

\section{CRISTINEL MORTICI}

Abstract. The aim of this paper is to establish a double inequality related to Gosper formula for approximation of big factorials

Mathematics subject classification (2010): 33B15, 41A10, 42A16.

Keywords and phrases: Gamma function, Stirling formula, Gosper formula, approximations.

\section{REFERENCES}

[1] B. C. Berndt, Y.-S. Choi, S.-Y. Kang, The Problems Submitted by Ramanujan, J. Indian Math. Soc., Contemporary Math. 236 (1999), 15-56.

[2] R. W. Gosper, Decision procedure for indefinite hypergeometric summation, Proc. Natl. Acad. Sci., USA 75 (1978), 40-42.

[3] S. RAMANUJAN, The lost notebook and other unpublished papers, Intr. by G. E. Andrews, Narosa Publ. H.-Springer, New Delhi-Berlin, 1988.

[4] J. STIRLING, Methodus differentialis, sive tractatus de summation et interpolation serierum infinitarium, London, 1730. English translation by J. Holliday, The Differential Method: A Treatise of the Summation and Interpolation of Infinite Series. 